\title{
El Dialogus pro ecclesia contra synagogam impreso por Pablo Hurus: autoría, fecha y transmisión manuscrita
}

\author{
Carmen Cardelle de HartmanN \\ Ludwig-Maximilians-Universität, Múnich
}

Hace unos pocos años Moisés Orfali publicó un curioso texto que había editado Gonzalo García de Santa María e impreso Pablo Hurus en Zaragoza a finales del siglo XV ${ }^{1}$. Califico el texto de curioso por la incongruencia entre el comienzo, con la creación de un marco narrativo para una disputa, y el desarrollo del tema.

Comienza con una pequeña narración: una hermosa joven, que va de Jericó a Jerusalén para presentar un sacrificio en el templo, encuentra a una anciana ciega. La anciana se presenta: su nombre es Synagoga y quedó ciega cuando inmolaba en el templo. La joven, compadecida, intenta llevarla de nuevo al camino. Ambas hacen una pausa en un lugar simbólico, una roca de la que manan dos riachuelos. La roca, dice el autor, es Cristo, el manantial su doctrina y los dos riachuelos los dos modos de interpretar la Escritura, literal y alegórico. La joven se coloca entre ambos y explica a la anciana el porqué de su ceguera. Synagoga no ha reconocido la fe verdadera y se ha apartado en solitario del camino de la verdad. Synagoga pregunta cuál es el nombre de la joven que osa hablarle así. Ecclesia es su nombre y anuncia a Synagoga que va a señalarle

\footnotetext{
1 Moisés ORFALI, «El Dialogus pro ecclesia contra synagogam: un tratado anónimo de polémica antijudía», Hispania 18 (1994) págs. 679-732.

Sefarad 62 (2002) págs. 3-19

(C) CSIC

ISSN 037-0894
} 
los errores que contiene el Talmud y a refutarlos, para luego demostrarle la verdad de la fe cristiana.

Hasta aquí la pequeña escena no carece de originalidad. Los debates entre Ecclesia y Synagoga no son infrecuentes, pero suelen presentarse con otros escenarios: normalmente ante la cruz, pero también ante un tribunal ${ }^{2}$. La continuación, sin embargo, sorprende. A partir de este momento el tono de disputa personal se pierde, las intervenciones de Synagoga son mínimas y la hermosa joven empieza a hablar como un escolástico, estructurando sus intervenciones con muletillas académicas, como primo ... contra ... item ... contra. El diálogo se convierte prácticamente en un tratado a pesar de las -pocas- frases de Synagoga. El tono sorprende incluso si se compara el texto con otros diálogos de tono didáctico de la época. La escena inicial no se retoma y el diálogo llega a su fin sin que se vuelva a aludir a ella y sin que se resuelva la situación planteada.

Otro punto de interés en el diálogo son las informaciones sobre la organización del Talmud y las pequeñas historias tomadas de éste que Ecclesia narra. Unas y otras muestran que el autor estaba familiarizado con el Talmud.

Gonzalo García de Santa María dice en su prólogo haber encontrado el texto en un manuscrito que no mencionaba al autor. Orfali atribuye el diálogo al dominico francés Thibaut de Sézanne, posible colaborador en la elaboración de un dossier sobre el Talmud presentado a Eudes de Châteauroux durante la disputa sobre el Talmud en París a mediados del siglo XIII ${ }^{3}$.

\footnotetext{
2 Ante un tribunal disputan ambas matronas en la Altercatio Ecclesiae et Synagogae, ed. J. N. HILLGARTH, CC SL 69a (Turnhout 1999), un texto probablemente del siglo V atribuido en la Edad Media a Agustín. Más frecuente es la presentación de Synagoga y Ecclesia como madre e hija junto a la cruz; así lo encontramos en un diálogo de Gilbert de Tournai, en algunos poemas franceses y en representaciones teatrales alemanas. Sobre ello véase Hiram Pflaum [PERI], Die religiöse Disputation in der europäischen Dichtung des Mittelalters, I: Der allegorische Streit zwischen Synagoge und Kirche (Ginebra - Florencia 1935). Sobre la literatura mediolatina de polémica religiosa en forma dialogada vid. Carmen CARDELLE DE HARTMANN, «Diálogo literario y polémica religiosa en la Edad Media», en Actas del Congreso Internacional «Cristianismo y tradición latina», eds. A. Alberte y C. Macías (Málaga 2001) págs. 103-123.

${ }^{3}$ Esta es también la opinión de Gilbert DAHAN, «Les traductions latines de Thibaut de Sézanne», en Le brûlement du Talmud à Paris 1242-44, ed. Gilbert DAHAN (París 1999) págs. 95-120 (volumen con las actas de un coloquio internacional celebrado en París, 2-3 de mayo de 1994).
} 
En estas páginas quiero hacer una propuesta alternativa de datación y autoría, además de informar sobre la transmisión del texto según los manuscritos que he podido localizar. Para situar el escrito en su contexto voy a referirme brevemente al trasfondo histórico: la polémica contra el Talmud del siglo XIII. Pasaré luego a considerar al dominico Thibaut y las obras que se le atribuyen, para terminar planteando la relación del diálogo del que nos ocupamos con esas obras y haciendo una propuesta sobre época y autoría.

\section{TRASFONDO HISTÓRICO}

El trasfondo de tales escritos es la polémica contra el Talmud de mediados del siglo XIII. Ya en el XII el converso hispano Pedro Alfonso y el abad de Cluny Pedro el Venerable habían polemizado contra el Talmud, sobre todo contra los elementos mágicos y tradicionales de la agadá ${ }^{4}$. Sus críticas, sin embargo, no encontraron eco entre sus contemporáneos.

Durante el siglo XII la relación entre judíos y cristianos se va deteriorando progresivamente en Europa Central ${ }^{5}$. Significativo es el decreto promulgado por el IV Concilio Laterano, que ordena la separación de las viviendas de cristianos y judíos y que estos últimos lleven signos distintivos. El ambiente es, pues, ya tenso en 1240 , cuando un converso francés, Nicolas Donin (bautizado en 1236), denuncia ante el Papa Gregorio IX que los judíos ya no siguen la ley del Antiguo Testamento, sino la ley del Talmud, contra el que presenta 35 acusaciones ${ }^{6}$.

\footnotetext{
${ }^{4}$ Petri Venerabilis adversus Judaeorum inveteratam duritiem, ed. Yvonne FRIEDMAN (Turnhout 1985). Sobre este autor véase también Yvonne FrIEDMAN, «Anti-Talmudic Invective from Peter the Venerable to Nicholas Donin", en DAHAN Le brûlement págs. 171-189, donde la autora compara los argumentos de Pedro con los de Nicholas Donin. El diálogo de Pedro Alfonso lo ha editado Klaus Peter Mieth, Der Dialog des Petrus Alfonsi, seine Überlieferung im Druck und in den Handschriften; Textedition (Berlín 1982); texto de Mieth con traducción al español de Esperanza DUCAY y prólogo de John Tolan, Pedro Alfonso de Huesca: Diálogo contra judíos (Huesca 1996). Sobre la recepción de la obra véase John TOLAn, Petrus Alfonsi and his Medieval Readers (Gainesville Fl. 1993).

${ }^{5}$ Sobre esos cambios del siglo XII véanse sobre todo las siguientes obras de reciente aparición: Anna Sapir ABULAFIA, Christians and Jews in the Twelfth-Century Renaissance (London - New York 1995); Robert CHAZAN, Medieval Stereotypes and Modern Antisemitism (Berkeley - Los Angeles 1997); y Alfred HAVERKAMP (ed.), Juden und Christen zur Zeit der Kreuzzüge (Sigmaringen 1999).

${ }^{6}$ Resumo los hechos conocidos siguiendo a A. TUILIER, «La condamnation du Talmud par les maîtres universitaires parisiens: Ses causes et ses conséquences politiques et idéologiques», en DAHAN Le brûlement págs. 7-20 (con bibliografía
} 
La denuncia es de mucho peso. El motivo siempre aducido para respetar a los judíos era el considerarlos guardianes de la hebraica veritas, la letra de la Biblia, y testigos de la verdad y la vigencia del Antiguo Testamento. Pero si los judíos han dejado de seguir la ley bíblica, se han convertido en herejes ${ }^{7}$ y como tales han de ser perseguidos y corregidos.

Como reacción a las acusaciones de Donin, el Papa escribe a los soberanos cristianos de Inglaterra, Francia y los reinos hispanos pidiéndoles que confisquen los libros judíos y comprueben si esas acusaciones tienen base. Sólo Luis IX de Francia sigue las instrucciones papales y hace requisar los libros judíos. Poco después se organiza una disputa en la que preside la delegación judía el rabí Yehiel de París y la cristiana el arzobispo de Sens, Gautier Cornut. Como resultado de este proceso se ordena una quema pública (o quizá varias) del Talmud. El 9 de mayo de 1244, el nuevo Papa Inocencio IV escribe a Luis IX insistiendo en que se realice la quema; pero tres años más tarde cambia de opinión y escribe a su legado Eudes (Odo) de Châteauroux (también llamado de Tusculum), pidiéndole que reconsidere el asunto y expurgue los ejemplares del Talmud de errores en vez de quemarlos. Este proceder le parece a Eudes impracticable y el asunto se cierra con la condena definitiva del Talmud el 15 de mayo de 1248, en la Sententia Odonis.

En la Bibliothèque Nationale de París se conserva un códice (lat. 16558), conocido con el nombre Extractiones de Talmut, que reúne toda una serie de documentos y materiales relacionados con el caso y sobre todo una colección de textos procedentes del Talmud y traducidos al latín, utilizados sin duda para que los representantes cristianos se formaran una idea de su contenido ${ }^{8}$.

sobre los sucesos que tuvieron lugar entre 1240-1248 en págs. 243-246), y Alexander PATSCHOVSKY, «Der 'Talmudjude'. Vom mittelalterlichen Ursprung eines neuzeitlichen Themas», en Juden in der christlichen Umwelt während des späten Mittelalters, eds. Alfred HAVERKAMP y Franz-Josef ZIwES (Berlín 1992) págs. 13-27.

${ }^{7}$ En el texto editado por Orfali aparecen una y otra vez afirmaciones explícitas en este sentido: «... quod est heresis» (pág. 693 líns. 37-38), «... quorum utrumque est heresis» (pág. 694 lín. 19), «... quod est blasphemia» (pág. 695 lín. 7), «... quod est blasphemia et heresis» (pág. 695 lín. 43 a pág. 696 lín. 1).

${ }^{8}$ El contenido del códice lo describe DAHAN «Les traductions» págs. 118-120. Véase también PATSCHOVSKY «Der Talmudjude» págs. 18-19. 


\section{El DOMINICO THIBAUT Y LAS OBRAS QUE SE LE ATRIBUYEN}

Entre los colaboradores de Eudes se menciona en la Sententia Odonis un cierto «frater thaobaldus de saxannia». Esta Saxannia (o Sexannia) debe de ser Sézanne (dep. Marne) ${ }^{9}$; lo poco conocido del topónimo y su semejanza con Saxonia ha provocado que en no pocos catálogos se mencione a este personaje como Theobaldus de Saxonia o incluso Theobaldus Saxo.

Por un manuscrito conservado en Múnich ${ }^{10}$ sabemos que era converso del judaísmo y subprior del convento de dominicos parisino. Con su nombre y título de subprior (pocas veces superior, probablemente por error de copia), se le menciona en la mayor parte de los manuscritos como autor de un tratado titulado Obiectiones in Talmut Judaeorum o Errores Judaeorum in Talmut (éstas son las dos formas más frecuentes del título, que se repiten con pequeñas variaciones) ${ }^{11}$. En este tratadillo se hace una pequeña explicación de la estructura del Talmud y se recogen una serie de historias procedentes de éste, muy probablemente a través de las traducciones del dossier parisino. Las historias sirven para denunciar elementos irracionales del judaísmo o mostrar el odio de los judíos hacia los cristianos.

Los Errores aparecen en muchos manuscritos acompañados de otro tratado anónimo, titulado Pharetra fidei catholice, en el que se presentan argumentos y textos bíblicos adecuados para la defensa de los artículos básicos de la fe cristiana, así como instrucciones para reaccionar a posibles argumentos de los judíos. En algunos manuscritos ambos tratados aparecen reunidos bajo el título

\footnotetext{
${ }^{9}$ Los pocos datos que se conocen sobre Thibaut los reúne DAHAN «Les traductions» págs. 99-101.

${ }^{10}$ Múnich, Bayerische Staatsbibliothek (clm 26847), procedente del convento de dominicos de Ratisbona, f. 68r.

${ }^{11}$ Los datos que se dan aquí sobre la transmisión textual se basan en el examen de los códices de la Bayerische Staatsbibliothek de Múnich que contienen el tratado. Unos sólo contienen los Errores (clm 101, clm 3070, clm 3243, clm 4350, $\operatorname{clm} 4460, \operatorname{clm} 5660, \operatorname{clm} 18365, \operatorname{clm} 22377, \operatorname{clm} 23833, \operatorname{clm} 23923, \operatorname{clm} 26727, \mathrm{clm}$ 26842, clm 28251, clm 28529); otros sólo contienen Pharetra, obra de la que me ocupo más adelante (clm 14227 y clm 21573); y otros varios contienen ambas obras (Pharetra - Errores: $\operatorname{clm} 3762$, clm 4366, clm 5672, clm 5896, clm 7547, clm 7806, clm 9005, clm 9558, clm 14722, clm 15141, clm 16061; y Errores - Pharetra: clm 7557 y clm 14265); a los que hay que añadir algunos otros códices con fragmentos de Errores (clm 311 y clm 18363) o de Pharetra (clm 14553).
} 
común Pharetra, normalmente en el orden Pharetra - Errores y en alguna ocasión en el orden inverso; pero también han tenido vida independiente, más abundante en el caso de los Errores y menor para Pharetra. Pueden llevar un prefacio en el que se anuncia un tratado en dos partes, que corresponderían a Pharetra - Errores (en este orden; véase más adelante el texto); aunque también puede aparecer ese prefacio precediendo a uno solo de los tratados, o a ambos, pero cada uno con epígrafe propio. Tan variante transmisión provoca confusiones tanto en los catálogos como en la literatura secundaria, y pocas veces queda claro a qué tratado se hace referencia con el título Pharetra. En este trabajo me refiero a los tratados por separado como Pharetra y Errores y en conjunto como Pharetra - Errores.

El texto de los Errores presenta semejanzas con el dossier parisino de extractos del Talmud, pero como Gilbert Dahan ha observado ${ }^{12}$, mientras aquel se caracteriza por su exactitud y rigor, los Errores tienen un tono polémico. Tanto el prólogo que llevan muchos manuscritos, con instrucciones para el debate con judíos, como algunos pasajes del propio texto revelan la intención del autor: ofrecer un manual para la disputa. He aquí el texto del prólogo:

In disputatione contra Judeos notate triplicem cautelam. Prima est ut in primis disputationibus studeatis eorum errores reprobare, sicut habetis in secunda parte, tunc quia facilius est errores reprobare quam nostre fidei articulos probationibus declarare, tunc quia non proficiunt semina veritatis nisi prius extirpentur spine et tribuli falsitatis. Secunda cautela est ut obiectiones que uidentur esse contra nos non tangatis, nisi eas Judeus per se obiecerit, tunc solvite eas, sicut solutas invenietis. Tercia est ut quando pluribus Judeis presentibus disputatis omnibus silentium indicatis excepto uno respondente. Donec illo superato accedat alius responsurus, ne forte clamoribus vos obruant et etiam uno loquente alius interim evasionis diverticula studeat invenire.

Incipit pharetra fidei contra Judeos. Tolle arma tua pharetram et arcum ad vulnerandas volpeculas que demoliuntur vineas nostras et accipe gladium Spiritus quod est verbum Dei ut testimoniis legis et prophetarum superbus Goliath id est populus Judeo-

12 DAHAN «Les traductions» págs. 103-104. 
rum proprio gladio superetur. Distinguitur autem hoc opusculum in duas partes. In prima ponentur que pertinent ad fidei catholice probationem. In secunda parte que pertinent ad Judaycorum errorum reprobationem ${ }^{13}$.

Los tratados Pharetra - Errores tuvieron un éxito excepcional. Panella pudo reunir 137 manuscritos, casi todos en ámbito alemán (Alemania, Austria, Chequia), y siete ediciones incunables, además de una traducción al alemán; pero hay que contar con la existencia de bastantes más manuscritos ${ }^{14}$.

Tal copia de manuscritos va acompañada de una notable variación textual, lo que hace imprescindible no sólo una edición de los tratados, como la que ha anunciado Gilbert Dahan, sino sobre todo un detallado estudio de la transmisión textual en sus distintas versiones, como el anunciado por A. Patschovsky, en cuya realización ya trabaja desde hace algún tiempo ${ }^{15}$.

La difusión de los Errores en Europa central ha contribuido seguramente a configurar y propagar una determinada imagen de los judíos que se venía fraguando desde el siglo XII: seres irracionales que llegan a parecer inhumanos, movidos por el odio a los cristianos, peligrosos y blasfemos.

Un aspecto de extraordinario interés es el modo en que este tópico se transmitió a los seglares. En el siglo XV contribuyeron sin duda en gran medida las impresiones; en los siglos XIII y XIV hay que contar quizá con las disputas públicas, según el destino que el autor diera a su obra ${ }^{16}$, y desde luego con los sermones, en los que se recurriría a las historias que hemos mencionado como

${ }^{13}$ Según el códice de Múnich, Bayerische Staatsbibliothek (clm 16061, f. 124va).

${ }^{14}$ Thomas KaEPPEl - Emilio PANELla, Scriptores Ordinis Praedicatorum Medii Aevi (Roma 1993) vol. IV págs. 292-296. A la lista de Panella hay que hacer algunas correcciones; vid. al respecto mi artículo «Drei Schriften mit dem Titel Pharetra fidei», Ashkenas 11, 2 (2001) en prensa.

15 PANELla Scriptores pág. 296 anuncia la edición de Dahan, que este mismo confirma en «Les traductions» pág. 104 nota 45; y PATSCHOVSKY «Der Talmudjude» pág. 16 nota 11.

${ }^{16}$ El contexto de transmisión en algunos códices parece indicar que la obra se entendió como texto de polémica. En el códice de Múnich, Bayerische Staatsbibliothek (clm 28529), de fines del siglo XIV, a la Pharetra de Thibaut y los Errores (ff. 270 a 278 ) siguen en letra muy apretada (ff. 285 r a 286 r) unas instrucciones para el debate contra los judíos con el incipit: «Quandocumque loqueris cum Iudeo de passione Domini distingue quia secundum humanitatem passus». 
amenos exempla. Nicole Bériou ha encontrado huellas de tal uso en sermones de origen alemán ${ }^{17}$.

\section{EL DIALOGUS: FECHA Y AUTORÍA}

Un buen testimonio del éxito de los dos tratados lo ofrece el Dialogus impreso por Pablo Hurus. Efectivamente, este diálogo no es otra cosa que una nueva versión de los tratados, en el orden Errores - Pharetra, a los que se ha añadido un nuevo prefacio, la introducción escénica y las pocas intervenciones de Synagoga. Para una puntual comparación entre ambas obras en la que se pueda precisar hasta qué punto el autor del Dialogus ha modificado el texto original sería preciso tanto un estudio detallado de la transmisión de esta obrita, como, sobre todo, de Pharetra - Errores.

Entretanto he realizado una comparación entre el Dialogus editado por Orfali y el texto de Pharetra - Errores según el incunable Hain 15231 y varios manuscritos de Múnich, Bayerische Staatsbibliothek (clm $3762{ }^{18}, \mathrm{clm} 15141^{19}$, clm $16061^{20}$ y clm $\left.28529^{21}\right)$. De esta comparación resulta que el autor del Dialogus ha reproducido de manera casi literal el texto de Pharetra-Errores, con frecuentes abreviaciones, algunas trasposiciones, pocos añadidos -aparte de los necesarios para darle forma de diálogo-, y algunas supresiones. Como muestra de la forma en que se incorpora el texto de Pharetra - Errores, cito dos pasajes, la breve introducción al Talmud y un corto párrafo referido a la fiesta de Purim.

\footnotetext{
${ }^{17}$ Nicole BÉRIOU, «Entre sottises et blasphèmes: Échos de la dénonciation du Talmud dans quelques sermons du XIII ${ }^{\mathrm{e}}$ siècle», en DAHAN Le brûlement págs. 211237.

18 Procedente de la catedral de Augsburgo (papel), escrito en los años 14351437: Pharetra, ff. 249r-253v; Errores ff., 253v-257r.

19 Procedente de la colegiata de canónigos regulares de Rebdorf (papel), siglo XV: Pharetra, ff. 268r-272v; Errores, ff. 272v-277r.

${ }^{20}$ Procedente de la colegiata de San Nicolás en Passau (canónigos regulares de S. Agustín) (pergamino), principios del XIV o finales del XIII: índice con el título Pharetra y el contenido de Pharetra - Errores sin separación (f. 124ra-b); Pharetra, ff. 124va-130rb; Errores, ff. 130rb-135ra.

${ }^{21}$ Procedente del convento franciscano de Ingolstadt (papel), fines del siglo XIV: Pharetra, ff. 270r-278r; Errores, ff. 278r-285r.
} 


\section{Pharetra - Errores}

Talmut id est doctrina dividitur in IIIIor libros quorum quilibet appellatur Cesez in genere ut nos omnes libros vocamus bibliam. Habet tamen quilibet nomen speciale, primus vocatur Mohetz id est terminus, secundus Nassim id est mulieres, tercius Cysassym id est sanctuaria, quartus Jessuhoz id est salutationes. Hunc Talmut Judei preferunt Moysi et prophetis. Et ut magis ad credendum Talmut fabulis addunt fabulas dicentes quod [quod] Deus studeat in Talmut ${ }^{22}$.

\section{Dialogus}

Talmuth, id est doctrina, dividitur in IIII libros quorum quilibet appellatur Cezer in genere, habet tamen quodlibet nomen speciale. Primus vocatur mohoz id est terminus. Secundus vocatur Nassy, id est mulieres. Tercius cadasin, id est sanctuaria. Quartus jessuom, id est salutationes. Hoc Talmut preferunt judei libris moysi et prophetis, et vt magis ad credendum Talmut homines alliciant, fabulis addunt fabulas, dicentes quod Deus studeat in Talmut ${ }^{23}$.

\section{Pharetra-Errores}

In festo Mardochei qui sapientia sua et precibus liberavit eos a sententia mortis quam Aman impetraverat a rege Assuero super omnes Judeos, ut legitur in Hester, quod adhuc celebrant per singulos annos $\mathrm{XV}^{\circ} \mathrm{kal}$. Marcii, quociens nominatur Aman conterunt ollas in synagogis dicentes «sicut contritus est Aman, sic regnum christianorum velociter conteratur» 24 .

\section{Dialogus}

In festo Mardochei, quod adhuc celebrant XV. kalendas Marcii, quotiens nominatur Haman conterunt ollas in synagogis dicentes: «Sicut contritus est Haman, sic regnum Christianorum velociter conteratur» ${ }^{25}$.

\footnotetext{
${ }^{22}$ Múnich, Bayerische Staatsbibliothek (clm 16061, f. 130rb).

23 ORfali Dialogus pág. 693 líns. 29-36.

${ }^{24}$ Múnich, Bayerische Staatsbibliothek (clm 16061, f. 132 vb).

25 Orfali Dialogus pág. 700.
} 
Pese al buen comienzo del redactor con la escena que resumí al principio del artículo, los ánimos creativos parecen haberlo abandonado pronto. No sólo las intervenciones de Synagoga son escasas y poco inspiradas y la situación planteada queda sin resolución, sino que además desaprovecha algunos pasajes que invitan a la reformulación en forma de diálogo. Por ejemplo, suprime por completo el amplio pasaje en que se rebate la idea de la preexistencia de las almas; supresión que resulta curiosa, ya que en los Errores se dan instrucciones muy concretas para el debate que hubieran permitido una discusión ágil entre Ecclesia y Synagoga. Véase como muestra de esas instrucciones el siguiente pasaje:

... et obic: quero a te iudee ubi anima tua fuit ante infusionem in corpus, utrum fuerit in celo empireo vel aereo vel sydereo vel paradiso. Si dicit quod in celo empireo quere utrum sint novem chori angelorum et fac eos tibi ordinem numerare et quere quos sanctos ibi viderit et de officiis angelorum. Si dicit quod in celo sidereo quere de septem planetis et de virtute eorum etc. ${ }^{26}$

El texto base del diálogo es, pues, como había avanzado Orfali, obra de Thibaut de Sézanne o deriva de una obra de este autor. Pero ahora se plantea la cuestión de quién transformó su texto en diálogo y también sigue sin resolverse la cuestión de la fecha, ya que la datación de Orfali a mediados del siglo XIII se basa en las referencias a la quema del Talmud y a Luis IX, procedentes de los Errores.

Para avanzar una propuesta sobre esos puntos tenemos que lanzar una mirada a la transmisión manuscrita.

Quizá el primero en llamar la atención sobre el diálogo fue Labrosse en su repertorio de las obras de Nicolás de Lyra ${ }^{27}$, en el que ya rechazaba tal atribución y proponía a Thibaut como autor. Con indicaciones poco precisas, Labrosse se refiere a los siguientes manuscritos que transmiten el diálogo (he comprobado y completado sus referencias) ${ }^{28}$ :

${ }^{26}$ Códice clm 28529, f. 282v.

27 Henri LABRosse, «Oeuvres de Nicolas de Lyre», Etudes Franciscaines 19 (1908) págs. 41-52, 153-175, 368-379; 35 (1923) págs. 171-187 y 400-432 (sobre el Dialogus 416-418).

${ }^{28}$ La información sobre los manuscritos está tomada de los catálogos citados. Los códices de Múnich los he examinado en persona; en los de Viena, comprobó incipit y explicit (que no los proporcionaba el catálogo) la bibliotecaria Dña. Maria Kröpfl, a quien le doy las gracias por su amabilidad. 
- Erfurt, Wissenschaftliche Allgemeinbibliothek, Amplonianische Handschriftensammlung (quarto 82), segunda mitad del siglo XIV (hasta el f. 97, papel) y mediados del siglo XIV (a partir del folio 98, pergamino). El diálogo lleva el título: Pharetra christianorum eiusdem contra Judeos (ff. 130-148) ${ }^{29}$.

- Erfurt, Wissenschaftliche Allgemeinbibliothek, Amplonianische Handschriftensammlung (quarto 116), datado el 6 de julio de 1401. Título: Pharetra fidei catholicae contra iudeos (ff. 204-216) ${ }^{30}$.

- Múnich, Bayerische Staatsbibliothek (clm 3243; papel), datado en el año 1447, procedente del monasterio benedictino de Ansbach. Título: Tractatus contra Judeos; una segunda mano ha añadido «M. Nicolai de Lyra» (ff. 203r-218r) ${ }^{31}$.

- Rouen, Bibliothèque Municipale (3019; collection Leber, 59), siglo XIV. Incipit (f. 4): «Isti sunt errores de Talmuth a Judeo baptizato. Primo igitur errores de Talmuth declaremus. Talmuth, id est doctrina, dividitur in quatuor libros ...»; explicit: «... locutus sum ut facerem ei. Expliciunt obiectiones sive redargutiones ecclesie contra errores cuiusdam libri Judaeorum qui dicitur Talmuth» (ff. 1-7) ${ }^{32}$.

En el incipitario In principio se encuentran además referencias a los siguientes manuscritos:

- Brno, Státní Vedecká Knihovna (Mk 43; II. 148), siglo XIV. Título: Thalamut sive Disputatio contra Judaeos; explicit: «...

${ }^{29}$ Wilhem SCHUM, Beschreibendes Verzeichnis der Amplonianischen Handschriften-Sammlung zu Erfurt (Berlín 1887) págs. 348-349.

${ }^{30}$ SCHUM Beschreibendes Verzeichnis págs. 374-375.

${ }^{31}$ C. HAlm et al., Catalogus codicum latinorum Bibliothecae Regiae Monacensis, vol. I parte 2 (Múnich 1878; reimpr. Wiesbaden 1969) pág. 71 (examinado directamente).

${ }^{32}$ Catalogue Général des Manuscrits des Bibliothèques Publiques de France, Départements 2, 2 (París 1885), pág. 72. He solicitado a la biblioteca de Rouen informaciones sobre la procedencia del códice. La bibliotecaria Dña. Claudine Brabetz, a quien doy aquí las gracias, tuvo la amabilidad de proporcionarme los siguientes datos. El manuscrito formaba parte de la colección de Jean Michel Constant Leber (1780-1859), vendida a la Biblioteca de Rouen el 19 de marzo de 1838. La colección fue reunida por el mismo Leber, pero se ignora dónde adquirió el códice. 
unde cum psalmo dicamus: in manus tuas domine, commendo spiritum meum» (ff. $1 \mathrm{r}-18 \mathrm{r})^{33}$.

- Klosterneuburg, Bibliothek des Chorherrenstifts (933, $\mathrm{n}^{\circ} 49$ ). Título: Tractatus de haereticis; explicit: «ostendit se in vero corpore humano pastoris» (ff. 239-248) ${ }^{34}$.

- Colonia, Historisches Archiv (GB $4^{\circ}$ 66), procedente del monasterio Groß St. Martin (Colonia); la parte del códice en que se encuentra el diálogo fue escrita hacia 1470. Título (f. 25r): Parisienses errores excepti de Thalamut quos transtulit frater Theobaldus supprior ordinis predicatorum in villa; explicit: «... a suis erroribus celerius resipiscant. Et hec de erroribus Judeorum per nunc dicta sufficiant. Que omnia et singula vel quasi excerpta sunt ex libro fratris Theobaldi subprioris Parisiensis predicti vel ex compendio fratris Nicolai de Argentina et ex libro Petri Alphuncii etc.» (ff. 24r-39r) ${ }^{35}$.

- Graz, Universitätsbibliothek (312; papel), escrito hacia 1400, procedente de la colegiata de Seckau. El texto (ff. 2-15) está manco del último folio ${ }^{36}$.

- Graz, Universitätsbibliothek (873; papel), escrito en los años 1421 a 1437, procedente del convento cisterciense de Neuberg. Título: Pharetra fidei catholice contra Judeos; explicit: «... que stabit in loco, quasi sit Deus» (ff. 129v-148v) ${ }^{37}$.

- Londres, British Library (Royal 8 F XI; papel), finales del siglo XIV, procedente de Colonia (cf. f. 2: «istud opus emi in Colonia in ecclesia assumpcionis beate virginis anno dom. 1401 a quodam magistro arcium»). Texto en ff. 43-61 ${ }^{38}$.

${ }^{33}$ Vladislav DoKouPIL, Soupis rukopisù mikulovské Dietrichsteinské KnihovnyCatalogus codicum manu scriptorum Bibliothecae Dietrichsteinianae Nicolspurgensis (Prag 1958) pág. 86.

${ }^{34}$ Catálogo manuscrito del monasterio, reproducido por la Hill Monastic Manuscript Library.

35 Joachim VENNEBUSCH, Die theologischen Handschriften des Stadtarchivs Köln (Colonia 1980) pág. 70.

${ }^{36}$ Anton KERN, Die Handschriften der Universitätsbibliothek Graz, vol. I (Leipzig 1942) pág. 170.

37 KeRn Die Handschriften vol. II (Leipzig 1956) pág. 92.

${ }^{38}$ George WARNER - Julius GILSON, Catalog of Western Manuscripts in the old Royal and King's collections. British Museum, vol. I (Londres 1921) págs. 268-269. 
- Salzburg, Benediktiner-Erzabtei St. Peter, Stiftsbibliothek (b.VI.11; papel), escrito en el año 1437. Título: Pharetra fidei christianae contra Judaeos $\left(\mathrm{n}^{\circ}\right.$ 9, ff. 143r-171v) ${ }^{39}$.

- Viena, Österreichische Nationalbibliothek (362; pergamino), siglo XIV. Título: Pharetra contra Judeos (ff. 181v-188v) ${ }^{40}$.

- Viena, Österreichische Nationalbibliothek (4180; papel), siglo XV. Título: Pharetra fidei christianae contra iniquos Judaeos (ff. 26r-42v) ${ }^{41}$.

Por último, he podido localizar estos otros dos códices:

- Maguncia, Stadtbibliothek (I 130; papel), segunda mitad del siglo XV, procedente del monasterio cartujo de Maguncia. Explicit: «... penitentiam agam super bono quod locutus sum facere ei» (ff. $24 v-55 v)^{42}$.

- Múnich, Bayerische Staatsbibliothek (clm 19610; papel), escrito el año 1468, procedente del monasterio de Tegernsee. Título: Dialogus inter Synagogam et Ecclesiam de variis erroribus Talmuth judeorum aut stultiis variis (ff. 134r-141r) ${ }^{43}$.

Como puede verse, el diálogo lleva con frecuencia en los manuscritos el título de Pharetra. Me refiero a él, sin embargo, como Dialogus para evitar confusiones con la Pharetra que le sirve de base.

La transmisión manuscrita nos permite concretar un poco la datación. Término post quem son por supuesto los años $40 \mathrm{del}$ siglo XIII, en los que tuvo lugar la disputa sobre el Talmud y se redactó el dossier del que procede el material contenido en los Errores. El término ante quem nos lo da el códice más antiguo: el manuscrito de Erfurt, de mediados del siglo XIV.

En los manuscritos encontramos también algunas atribuciones de autoría, que en varios casos se adjudica a Nicolás de Lyra,

\footnotetext{
${ }^{39}$ Catálogo manuscrito del monasterio, reproducido por la Hill Monastic Manuscript Library.

${ }^{40}$ Tabulae codicum manu scriptorum praeter Graecos et Orientales in Bibliotheca Palatina Vindobonensi asservatorum, vol. I (Viena 1864, reimpr. Graz 1965) págs. 54-55.

41 Tabulae codicum vol. III (Viena 1968, reimpr. Graz 1965) pág. 194.

${ }^{42}$ Gerhard LIST - Gerhardt POwITZ, Die Handschriften der Stadtbibliothek Mainz, vol. I (Wiesbaden 1990) pág. 233.

${ }^{43}$ Halm Catalogus ... Bibliothecae Regiae Monacensis vol. II parte 2, pág. 259.
} 
aunque ya Labrosse demostró que esa atribución resulta muy improbable. Así, en el códice de Múnich (clm 3243) el diálogo se atribuye a dicho autor, pero al examinar el manuscrito advertimos que se trata de algo sin fundamento. El nombre de Nicolaus de Lyra junto al título (f. 203r) lo ha añadido una segunda mano, y el motivo del error resulta evidente: a nuestro diálogo le sigue sin solución de continuidad el tratado Responsio ad quendam Judaeum de Nicolás de Lyra ${ }^{44}$, sin que medie entre ambos textos ninguna separación o inicial que indique a simple vista dónde termina un texto y empieza el otro. Esta Responsio termina con las palabras «Explicunt responsiones magistri Nicolay de Lyra contra quendam iudeum ex verbiis Evangelii secundum Mattheum nequiter arguentem tractatus utilis» (f. 235r). Parece que el autor de la anotación pensó que se trataba de una sola obra rematada con ese colofón.

Labrosse se refiere asimismo al manuscrito de Viena, Österreichische Nationalbibliothek (3496; ff. 99r-101r), en el que el diálogo aparece también atribuido a Nicolás. Pero he comprobado el texto en reproducción fotográfica y se trata en realidad de la Pharetra precedida del epígrafe: «Incipit Pharetra fidei magistri Nicolai de Lira contra versucias hereticorum ac infideles judeos».

Queda el manuscrito de Erfurt, Amplonianische Handschriftensammlung (quarto 82), en el que el Dialogus sigue a un tratado de Nicolás de Lyra. La atribución a Nicolás se hace de forma indirecta en el epígrafe del Dialogus: «Pharetra christianorum eiusdem contra Judaeos», y quizá el que un texto siga al otro es lo que ha provocado el error del escriba.

En el manuscrito de Colonia encontramos otra atribución que resulta más probable. El escriba (1470) ha escrito: «Que omnia et singula vel quasi excerpta sunt ex libro fratris Theobaldi subprioris Parisiensis predicti vel ex compendio fratris Nicolai de Argentina et ex libro Petri Alphuncii ...». El autor de estas líneas ha leído con atención el texto y es además un lector informado: no sólo ha reconocido el texto comúnmente atribuido a Thibaut, sino que además se ha dado cuenta de que algunos pasajes del Talmud citados por Thibaut también los cita Pedro Alfonso. En mi opinión, este desconocido escriba merece que se le preste atención.

${ }^{44}$ Inédito, número 5 del repertorio de Labrosse. 
¿Quién es ese Nicolás de Estrasburgo (Argentina)? En ningún caso puede tratarse del cartujo Nicolás Kempf, nacido hacia 1414 y fallecido en 1497, aunque también es conocido como Nicolás de Estrasburgo. Más verosimil es su identificación con el dominico Nicolás, llamado Nicolás de Estrasburgo, lector de teología en el studium generale de su orden en Colonia y visitador de la provincia de Teutonia de la orden de Predicadores en 1325. En su oficio de visitador descargó al místico Eckhart de las acusaciones que pesaban contra él, por lo que se le encausó como impeditor inquisitionis ante el tribunal del arzobispo de Colonia. En el año 1331 el Papa Juan XXII intervino a su favor, solicitando al arzobispo una revisión de la sentencia ${ }^{45}$.

Nicolás de Estrasburgo se sitúa dentro de los márgenes temporales que hemos señalado. Además conocemos otra obra suya que es el fruto de una adaptación similar a la que hemos descrito para el Dialogus, es decir, la manipulación de obras anteriores: el tratado De adventu Christi et Antichristi et de fine mundi. Denifle ${ }^{46}$ fue el primero en señalar que la primera y la tercera parte de este tratado no son sino el resultado de la ligera adaptación por Nicolás de otros dos de Johannes Parisiensis, conocido como Jean Quidort ${ }^{47}$. La segunda parte parece ser obra propia de Nicolás, a pesar de las sospechas de Denifle de que pudiera estar también tomada de otro autor.

Denifle condena a Nicolás como plagiario y sospecha que obró con el deliberado propósito de apropiarse del trabajo de Quidort; pero conociendo la actitud medieval ante el plagio debemos suavizar un poco su juicio. Los autores medievales utilizan con frecuencia obras de otros autores, considerando que lo que es verdad pertenece a todos. Además, si se menciona al autor no es por pensar que este tenga derecho alguno sobre su propia obra, sino por consideración al lector, que tiene que saber quién hizo una afirmación

\footnotetext{
${ }^{45}$ Eugen HillenbRAND - Kurt RUH, «Nikolaus von Straßburg OP», en Die deutsche Literatur des Mittelalters. Verfasserlexikon. Zweite Auflage, vol. VI (Berlin - New York 1987) cols. 1153-1161.

${ }^{46}$ Heinrich DENIFLE, «Der Plagiator Nicolaus von Strassburg», Archiv für Literatur- und Kirchengeschichte des Mittelalters 4 (1888) págs. 312-329.

${ }^{47}$ Se trata de los tratados De adventu Christi secundum carnem (inédito; nr. 2575 en KAEPPELI Scriptores), y De adventu antichristi et fine mundi, editado por Sara Beth Peter Clark, The "Tractatus de Antichristo" of John of Paris: A Critical Edition, Translation, and Commentary (tesis: Cornell University 1981; University Microfilms International 1982; nr. 2576 en KAEPPELI Scriptores).
} 
para así estimar qué autoridad tiene y cuánto crédito ha de dársele. Por ello se establece toda una escala de autoridades, que empieza con la Biblia y termina con los escritos transmitidos anónimos y las obras de autores contemporáneos. Estos todavía no tienen autoridad, por lo que su nombre no resulta especialmente interesante para el lector y frecuentemente se omite ${ }^{48}$.

Con estas consideraciones de fondo se entiende mejor que el escriba de Colonia, que había reconocido perfectamente la obra de Thibaut, considere a Nicolás coautor por su -reducido a nuestro modo de ver- trabajo de adaptación.

Aunque suavicemos así la condena de Denifle, tenemos que reconocer que Nicolás realiza un trabajo de adaptación muy superficial. El dominico muestra además un cierto oportunismo al dedicar dos veces el De adventu Christi: al arzobispo Balduino de Tréveris en la época en que era lector en Colonia (entre 1323 y 1325), y al Papa Juan XXII en 1325.

El De adventu Christi et Antichristi et de fine mundi de Nicolás muestra pues el mismo modo de proceder que en el caso del Dialogus. Ambas obras tienen en común la relación con la polémica antijudía. Efectivamente, la primera parte del De adventu Christi et Antichristi trata de la prueba de algunas verdades de fe a través de la obra de autores paganos (Trinidad, encarnación, llegada del Mesías, temas constantes del debate entre cristianos y judíos). La parte central, obra del propio Nicolás, es una recopilación de pasajes del Antiguo Testamento utilizados en la polémica antijudía.

Esas semejanzas entre el Dialogus y el De adventu Christi et Antichristi, sumadas a la mención de Nicolás como autor en el manuscrito de Colonia, nos hacen considerar como muy probable su autoría. Incluso se podría precisar más la fecha de composición y centrarla en los años 20 del siglo XIV, época en la que Nicolás se ocupaba de la polémica antijudía y residía en Colonia, lugar del que proceden al menos dos de los manuscritos del Dialogus, el de Colonia y el de Londres.

\footnotetext{
${ }^{48}$ En contraste, Gonzalo García de Santa María se precia de su honradez al no apropiarse de un tratado que le llega como anónimo y al mismo tiempo lamenta que las obras anónimas carezcan de autoridad, poniéndola por ello bajo la protección del arzobispo de Sevilla Diego de Mendoza, a quien se la dedica. Sobre la idea medieval de plagio, véase Carmen CARDELlE DE HARTMANN, «Fures verborum alienorum: Plagiat im Mittelalter", en Text und Autor. Beiträge aus dem Venedig-Symposium 1998 des Graduiertenkollegs "Textkritik» München, eds. Christiane HENKES et al. (Beihefte zu editio. Bd. 15) (Tübingen 2000) págs. 85-95.
} 
Así pues, la obra tendría autor alemán y, a juzgar por la transmisión manuscrita, público alemán hasta su publicación en Zaragoza. La cuestión que se plantea es cómo llegó a manos de Gonzalo de Santa María. Quizá a través de los impresores alemanes asentados en Zaragoza con los que trabajó como corrector (uno de ellos el mismo Hurus) y con los que publicó traducciones del latín ${ }^{49}$. La conservación del Dialogus en el incunable de Hurus es en todo caso un dato que nos aparta de los auténticos autores y del público original.

\section{RESUMEN}

El Dialogus pro ecclesia contra synagogam editado por Gonzalo de Sta. María e impreso por Pablo Hurus a finales del s. XV fue atribuido por Labrosse, y más recientemente por Orfali, al dominico del s. XIII Thibaut de Sézanne (Theobaldus de Sexannia). En realidad, el Dialogus es una adaptación de dos tratados anteriores, Errores judaeorum in Talmut y Pharetra fidei catholicae, el primero de los cuales es atribuido a Thibaut en la transmisión manuscrita. El Dialogus está transmitido en catorce manuscritos, todos de origen centroeuropeo, presentados en este trabajo. En uno de ellos se nombra como autor a Nicolás de Estrasburgo OP, visitador de la provincia de Teutonia en 1325. Aquí se demuestra que, considerando algunos aspectos de la obra conocida de Nicolás, esta atribución es altamente probable.

\section{SUMMARY}

The Dialogus pro ecclesia contra synagogam was edited by Gonzalo de Santa María and printed by Pablo Hurus at the end of the $15^{\text {th }}$ century. It was attributed by Labrosse and, more recently, by Orfali to the $13^{\text {th }}$ century Dominican friar Thibaut de Sézanne (Theobaldus of Sexannia). In this article it is shown that the Dialogus is an adaptation of two older treatises, Errores judaeorum in Talmut and Pharetra fidei catholicae, the former attributed to Thibaut in the manuscript transmission. The Dialogus is transmitted in fourteen manuscripts; all of them come from Middle Europe and are listed here. In one of them the scribe attributes it to Nicholas of Strasbourg OP, visitor of the Dominican province of Teutonia in 1325 . This attribution seems to be highly probable in the light of some aspects of Nicholas' works.

49 J. MARTín ABAD, «Gonzalo García de Santa María: apuntes bio-bibliográficos», en Homenaje a Luis Morales Oliver (Madrid 1986) págs. 495-513. 